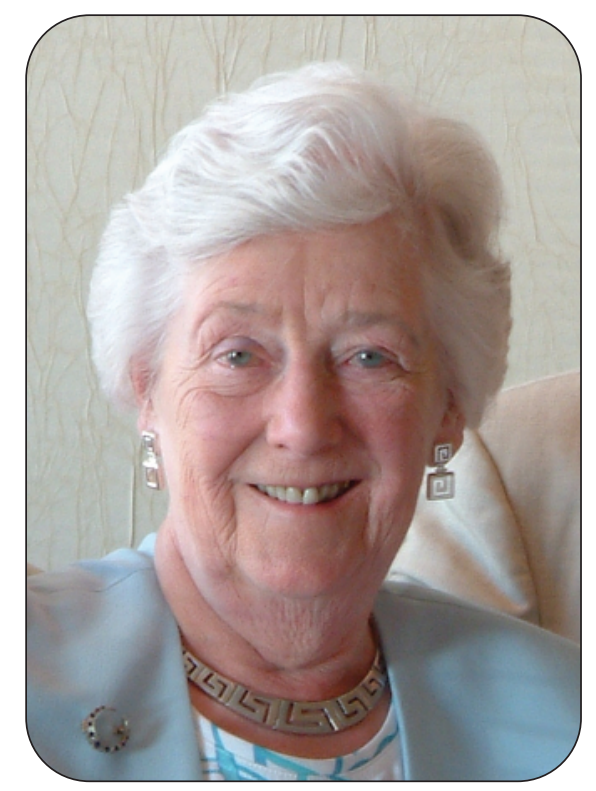

\title{
OBITUARY
}

\section{Dr Nancy Loudon OBE, MBChB, FRCPE, FFSRH}

Dr Nancy Loudon, formerly medical co-ordinator of the Lothian Family Planning and Well Woman Services, died in Edinburgh on 20 February 2009.

Nancy Mann was born in the Black Isle in 1926 into a large farming community and was the daughter of A J Mann, a prominent Ross-shire farmer and county councillor. She was Dux of Fortrose Academy and, in 1944, entered the Medical School in wartime Edinburgh. She excelled academically in her studies and obtained her medical degree with honours, one of only a handful of students to do so each year. She commenced work in the specialty of Obstetrics and Gynaecology, quickly becoming the registrar on the professorial unit, working under the supervision of Professor Robert Kellar. Her professional life changed dramatically when she became engaged to be married to a fellow gynaecologist, John Loudon. Professor Kellar declared that there was no place for a married woman in obstetrics and she was forced to resign her post. Ironically, 2 years later John Loudon was to accept Professor Kellar's registrar post, which Nancy had been forced to leave so abruptly.

Nancy's significant return to medical practice was a weekly session in the euphemistically named Edinburgh Mothers' Welfare clinic. This was Edinburgh's first family planning clinic and was run on a voluntary basis by two doctors, Maeve Marwick and Alexandra Lothian. In the early years, the clinic was based in old shop premises, where women sat on wooden benches and the building only possessed a cold tap. In 1957 a bequest of $£ 2000$ allowed the purchase of the current premises in Dean Terrace, carefully chosen for its secluded location. Contraception for women in these early days really only meant diaphragms, but in the early 1960s the contraceptive pill and intrauterine device became available. The clinic in Edinburgh quickly became a groundbreaking centre for these new methods as local women clamoured to benefit from the opportunity to delay and space their pregnancies. Nancy took over as Principal Medical Officer in 1972, and at that time the clinic was Branch 50 of the Family Planning Association (FPA) although it was to be subsumed later by Lothian Health Board.

The 1960s and 1970s were exciting but challenging times to be working in the contraceptive field. Nancy had a loyal and supportive team at the Dean Terrace clinic but faced huge battles, as many of the older medical professionals were initially hostile to the new developments. Contraception for unmarried women became another battleground. The clinic service expanded to offer well-woman screening, vasectomy, sexual problems clinics and place of work screening in local factories. Nancy was justifiably proud of establishing the Lothian Abortion Referral Service, which streamlined the management of women seeking abortion, cutting down unnecessary and distressing delays. She was able to pursue her academic medical interests with involvement in research studies on contraceptive steroid hormones leading to over 70 scientific publications. Her textbook, The Handbook of Family Planning, was first written in 1985 and has been a popular text for doctors working in the field; it pleased her greatly that the fifth edition, edited by Edinburgh colleagues, was recently published.

Nancy held a lectureship in the Department of Obstetrics and Gynaecology at the University of Edinburgh. She was chairperson of the UK National Association of Family Planning Doctors and held many other national medical roles. Following retirement in 1988, she was awarded the William Y Darling Bequest by Edinburgh District Council for Good Citizenship after a unanimous committee vote. In 1991 she became vice-chair of the newly established Health Education Board for Scotland and was subsequently elected a fellow of the Royal College of Physicians of Edinburgh. Her contribution to medicine was marked with an OBE in 1992.

Nancy was not afraid to challenge the establishment when the needs of women were threatened and could cut through red tape and bureaucracy with her critical thinking and persuasive manner. Very many people will remember and feel grateful to Nancy for her unfailing support and mentorship, loyal friendship and deep empathy for others when they were in difficult times. The 'Cinderella' medical specialty of Family Planning has now become firmly established in the UK with the Faculty of Sexual and Reproductive Healthcare; at the roots of its development and hard-won achievements were intelligent and articulate pioneering women like Nancy Loudon.

Nancy was hugely supported throughout her professional life by her husband, Dr John Loudon, retired consultant obstetrician and gynaecologist, and is also survived by her two sons and six grandchildren.

Submitted by Dr Ailsa E Gebbie, FRCOG, FFSRH, Consultant Gynaecologist, NHS Lothian, Family Planning and Well Woman Services, 18 Dean Terrace, Edinburgh EH4 1NL, UK 